IZA DP No. 5296

Addressing the Legacy Costs in an NDC Reform:

Conceptualization, Measurement, Financing

Robert Holzmann

Alain Jousten

October 2010 


\title{
Addressing the Legacy Costs in an NDC Reform: Conceptualization, Measurement, Financing
}

\author{
Robert Holzmann \\ World Bank \\ and IZA
}

\author{
Alain Jousten \\ University of Liège, \\ Netspar and IZA
}

\section{Discussion Paper No. 5296 \\ October 2010}

\author{
IZA \\ P.O. Box 7240 \\ 53072 Bonn \\ Germany \\ Phone: +49-228-3894-0 \\ Fax: +49-228-3894-180 \\ E-mail: iza@iza.org
}

Any opinions expressed here are those of the author(s) and not those of IZA. Research published in this series may include views on policy, but the institute itself takes no institutional policy positions.

The Institute for the Study of Labor (IZA) in Bonn is a local and virtual international research center and a place of communication between science, politics and business. IZA is an independent nonprofit organization supported by Deutsche Post Foundation. The center is associated with the University of Bonn and offers a stimulating research environment through its international network, workshops and conferences, data service, project support, research visits and doctoral program. IZA engages in (i) original and internationally competitive research in all fields of labor economics, (ii) development of policy concepts, and (iii) dissemination of research results and concepts to the interested public.

IZA Discussion Papers often represent preliminary work and are circulated to encourage discussion. Citation of such a paper should account for its provisional character. A revised version may be available directly from the author. 
IZA Discussion Paper No. 5296

October 2010

\section{ABSTRACT}

\section{Addressing the Legacy Costs in an NDC Reform: Conceptualization, Measurement, Financing}

The paper provides a framework for the conceptualization, definition and estimation of legacy costs that need to be addressed in a reform that transforms an unfunded defined contribution (NDB) scheme into a notional (or non-financial) defined contribution (NDC) scheme. As the new contribution rate is fixed and, perhaps, reduced, paying for the accrued to date liabilities leaves a financing gap that needs to be estimated and financed, best outside the pension system if a less distorting financing form is available. The paper illustrates the proposed measurement approach with broad estimates under a hypothetical NDC reform in China.

JEL Classification: H55, H68, J21, J26

Keywords: $\quad$ legacy costs, pension reform, NDC, coverage expansion

Corresponding author:

Robert Holzmann

Marseille Center for Mediterranean Integration

World Bank

Villa Valmer, 271 Corniche Kennedy

F-13007 Marseilles

France

Email: rholzmann@worldbank.org

\footnotetext{
* Revised paper presented at the Joint Swedish Social Insurance Agency - World Bank Conference on "Non-Financial Defined Contribution (NDC) Pension Systems: Progress and New Frontiers in a Changing Pension World", Stockholm, December 2-4, 2009. Very valuable comments and suggestions have been received from David Robalino, Florence Legros, Edward Palmer, 2 anonymous referees, and conference participants. For any remaining errors we take full responsibility. This paper reflects our own views and does in no case reflect the position and views of the organizations we are associated with.
} 


\section{Introduction}

When a pension reform is undertaken, the new systems typically aims at improved financial sustainability through a variety of measures including an increase in (future) retirement age and a reduction in (future) benefits. Both measures may also aim at a reduction in (future) steady-state contribution rates and better alignment between contribution and benefits of the scheme. But the legacy of existing commitments (due to acquired rights) to current and future retirees may not allow doing so directly as these commitments need to be partly or fully honored for social and political reasons. This raises the issue how this legacy issues should be best addressed and financed.

Keeping the contribution rate unchanged for the time being to keep the system financially afloat taxes current and future generations as they receive less benefits per unit of contribution. This (additional) tax element under parametric reforms has led to requests of financing this tax overhang or legacy costs through other public revenues that are less distortionary and thereby helping create the tighter contribution/benefit link that such reforms typically want to establish.

The argument of explicitly financing the legacy cost becomes even stronger under an NDC reform that fixes the contribution rate at future steady state levels. If such a decision is not taken, other approaches need to be applied that are akin to legacy cost financing of parametric reforms: Introducing an explicit tax element above the recorded contribution rate, unspecified increase in public transfers to the pension scheme, use of existing financial reserves, or benefit reductions beyond long-term financial needs. Such measures are typically not transparent and contribute little to enhance the credibility of the reformed scheme; the latter is in sharp contrast to the very objective of the reformed system.

While the arguments for an explicit financing of the legacy costs of pension reform seem strong, the actual practice looks bleak and unimpressive. No recent parametric reform has undertaken even a partial explicit financing of the legacy costs; the same applies to the NDC reforms introduced in Italy, Latvia, Poland and Sweden (see Palmer et al, 2010). While many good political economy arguments may explain such a behavior, it may also be the result of lacking interest in and guidance by the pension reform community on the topic. There is hardly any writing on how to define, how to measure and how to finance such legacy costs. To do so is the purpose of the paper and the suggested structure is as follows.

Section 2 outlines why it is important to explicitly address legacy costs in pension reforms in general and for NDC reforms in particular. Section 3 investigates alternative possibilities to conceptualize and define the legacy costs. Section 4 proposes alternatives how to estimate legacy costs while Section 5 reviews approaches and issues of how to finance them. Section 6 illustrates the measurement approach with broad estimates for a hypothetical NDC reform in China. Key conclusions are summarized in Section 7.

\section{Why is Important to Address Legacy Costs in an Explicit Manner?}

What are the key arguments to identify the legacy costs of a reform and finance them separately and outside the social security scheme via general revenues? And what are the key implications and considerations to take into account?

A key objective of pension reforms is to put the reformed system on a financially sustainable basis while adjusting the benefits system and their link to contributions in order to render the reformed system more equitable, affordable and less distortionary. This applies to parametric reforms as well as the move toward an NDC scheme. In many (or nearly all cases) this implies the move from a more generous toward a less generous benefit structure and a lower cost covering contribution rate for the future steady state. Simply keeping the inherited contribution rate for the new scheme in order to finance 
both the inherited higher (old) pensions and future lower (new) pensions means that the contribution rate would for some time contain an implicit tax component that would only gradually diminish over time. Keeping such a tax element purely implicit, however, contradicts the very objective of the reform.

An alternative is to separate both elements explicitly. The new NDC system with its fixed contribution rate expects the fiscal adjustment to take place through the benefit level and retirement age, levying contributions at the old contribution rate would make the tax element explicit. Only the NDC part of the contribution rate would be credited to the individual (notional) account, the remainder would be used to avoid a cash deficit for many years. While feasible, such an approach risks robbing the new NDC scheme from much of the expected better incentives, higher credibility and thus increase in formal labor force and system participation. While separating the costs for the older system from the reformed new system and financing via alternative budget revenues thus seems strongly suggested, such alternative financing needs to be less distortionary in economic terms and feasible in fiscal terms to be worthwhile to be undertaken. In addition, such separate financing of legacy costs raises a number of issues of its own that will not be addressed in this paper.

For example, intergenerational aspects are heavily influenced by the way transition costs are evaluated and financed. Any specific transition option will lead to different burden-sharing across generations -at least when generations are not linked in a way to generate Barro equivalence-like result. Put differently, the level of explicit and implicit debt shifted forward onto each younger generation is heavily dependent on the way the transition is organized and financed. For example, Feldstein, Ranguelova and Samwick (2001) provide a nice modelization that explicitly recognizes the intergenerational burden-sharing of an individual accounts reform in the US context. One interesting implication of these authors' calculations is that it also indicates the heavy dependence of outcomes for various generations (and thus the political acceptability of the reform) on the specifics of how the transition is implemented.

Similarly, intragenerational distribution will be affected by any reform. Such effects play at least on two levels, in terms of the reforms of the systems themselves as well as in terms of the financing of the transition. At the level of the system change, the shift from the existing system towards an NDC (or other) type of retirement system will almost inevitably lead to a change in the distributive characteristics of the pension system. For example, a shift from a more Beveridgean system towards NDC will likely benefit higher income earners in relative terms. Similarly, a risk-group-specific calculation of annuities would likely run counter to the interests of longer-lived people as compared to the common risk pool in conventional DB systems. At the level of the transition, various tax (or more broadly policy) instruments are non-neutral with respect to the intra-generational outcomes. For example, it is wellknown that Value-Added-Tax is often seen as a regressive tax instrument - in spite of the fact that it is riddled with exemptions and reduced rates to reduce the regressivity. ${ }^{1}$

\section{Conceptualizing the Legacy Costs}

Legacy costs can be defined in a first approximation as additional financing needs above and beyond those of the reformed and financially sustainable new system that reflect prior commitments. For these reason, the legacy costs are also sometimes called tax overhang as it reflects financing needs beyond the contribution revenues of the reformed system. While useful as a first approximation this definition is too broad and unspecific to guide policy decisions and cost estimations. We need to better understand what is in and what is outside the definition.

${ }^{1}$ See European Union (2007), Study on reduced VAT applied to goods and services in the Member States of the European Union, Final report prepared by Copenhagen Economics for DG Tax, Brussels. 
In order to conceptualize legacy costs we follow a stepwise approach by starting out within a simple three generation OLG model context in which we move from sustainable to unsustainable schemes to understand the key components of the legacy costs and key adjustments in contributions and benefits. The considerations within a model-type context should help better understand the critical but limited options to define legacy costs and the difference to other costs. Those issues get often blurred when looking straight into real-country situations. For those not interested in this thought process and the math involved, they can immediately go to the summing-up at the end of this sub-section. From there and in a second round we move toward the conceptualization in a more operational accounting framework that is more accessible for use in a country context and we investigate alternative approaches/indicators.

\section{i. Legacy Costs in Simple OLG Setting}

Let's start out with an OLG model with three generations. ${ }^{2}$ Thereby we focus on the financial situation of the pension scheme and assume that each generation works for 2 periods and is retired in the third. $\mathrm{N}$ is the size of the generation, $\mathrm{b}$ the benefit level, $\mathrm{c}$ the contribution rate, $\mathrm{w}$ the wage level (differentiated between old and young workers), and $t$ is the respective period we consider.

\section{Steady State - no deficit}

We start out with the steady state without deficit in which in each period 2 generations of workers (one old -0 , one young $-y$ ) finance the benefits of the generation that was an old worker one period, and a young worker 2 periods before.

\begin{tabular}{|c|c|c|c|c|}
\hline & $t-1$ & $\mathrm{t}$ & $t+1$ & $t+2$ \\
\hline E(xpendture) & $b_{t-1} N_{t-3}$ & $\mathrm{~b}_{\mathrm{t}} \mathrm{N}_{\mathrm{t}-2}$ & $b_{t+1} N_{t-1}$ & $b_{t+2} N_{t}$ \\
\hline $\mathrm{R}^{\mathrm{O}}$ (evenue) & $C w_{t-1}^{\circ} N_{t-2}$ & $\mathrm{C} \mathrm{w}^{\circ}{ }_{\mathrm{t}} \mathrm{N}_{\mathrm{t}-1}$ & $\mathrm{C} \mathrm{w}_{\mathrm{t}+1}^{\mathrm{o}} \mathrm{N}_{\mathrm{t}}$ & $\mathrm{C} \mathrm{w}_{\mathrm{t}+2}^{\mathrm{o}} \mathrm{N}_{\mathrm{t}+1}$ \\
\hline $\mathrm{R}^{\mathrm{y}}$ (evenue) & $C w_{t-1}^{y} N_{t-1}$ & $c w^{y}{ }_{t} N_{t}$ & $c w_{t+1}^{y} N_{t+1}$ & $\mathrm{C} \mathrm{w}_{\mathrm{t}+2}^{\mathrm{o}} \mathrm{N}_{\mathrm{t}+2}$ \\
\hline B(alance) & 0 & 0 & 0 & 0 \\
\hline
\end{tabular}

From the balancing condition (1) we can calculate the benefit level and simplify the expression (2) by inserting constant generational growth rates for wages ( $\mathrm{g}$ ) and size of generations $(\mathrm{n})$. Differentiating by time and after some simplification gives us an approximation for the growth rate of benefits (or internal rate of return, IRR). In expression (3) the well known result about the IRR being equal to growth rate of wage (i.e. productivity) plus growth rate of generation size (i.e. labor force) has an additional item - the change in turnover duration ${ }^{3}$. This is the money-weighted average time a contribution unit stays in the system before getting disbursed. In our steady-state model the turnover ratio is constant and hence the change $(\delta)$ zero. In reality and multi-generation OLGs this is not the case and has some bearing on measuring and financing the legacy costs.

\footnotetext{
${ }^{2}$ We introduce the model in rather general notation, but will at times simplify without loss of generality.

${ }^{3}$ For more generation presentations of the internal rate of return and further references, see Settergren and Boguslaw (2006) and Robalino and Bodor (2009).
} 


$$
\begin{aligned}
& b_{t} N_{t-2}=c w^{0}{ }_{t} N_{t-1}+c w^{y} N_{t} \\
& b_{t}=c w^{o}{ }_{t}\left(N_{t-1} / N_{t-2}\right)+c w^{y}{ }_{t}\left(N_{t} / N_{t-2}\right)=c(1+g)(1+n)[(1+g)+(1+n)] w^{y}{ }_{t-1} \\
& b \% \approx g+n\{+\delta\}
\end{aligned}
$$

\section{Moving from a higher to a lower benefit level}

For our next consideration we can move without loss of generality to a static model in which $\mathrm{g}$ and $\mathrm{n}$ are zero. As wages and derived benefits are constant we can drop the time index of the variables. We only keep it for $\mathrm{N}$ to indicate the cohorts across time.

We assume that the society wants to move toward a lower contribution rate and benefit level (half of the original one) while respecting acquired rights. Starting the reform in year $t$ means that the benefit and expenditure level are unchanged while contribution revenues are already reduced. Reducing the contribution rate immediately for all working generations leads to a shortfall of half of the original expenditures or revenues in period $t$. This shortfall is halved in period $t+1$ as the benefit levels could already be reduced without infringing on acquired rights. In period $t+2$ the new steady state is reached. A reverse time profile of the balance would be achieved if only the generation of labor market entrants were to be subject to a contribution cut.

$\begin{array}{lllll} & t-1 & t & t+1 & t+2 \\ R^{0} & b N_{t-3} & b N_{t-2} & b(3 / 4) N_{t-1} & b / 2 N_{t} \\ R^{v} & c w N_{t-2} & c / 2 w N_{t-1} & c / 2 w N_{t} & c / 2 w N_{t+1} \\ B & c w N_{t-1} & c / 2 w N_{t} & c / 2 w N_{t+1} & c / 2 w N_{t+1} \\ & 0 & -b N / 2 & -b N / 4 & 0\end{array}$

The legacy costs of this pension reform are the present values of the balances in the transition period [$\mathrm{cwN}(3 / 2)$ or $-\mathrm{bN}(3 / 4)]$ that equal the reduction of the implicit pension debt (or accrued to date liabilities). The pension debt at the beginning of period $t$ consists of the liabilities to the generation of retirees in this period $\left(\mathrm{N}_{\mathrm{t}-2}\right)$ and to the generation of older workers $\left(\mathrm{N}_{\mathrm{t}-1}\right)$ that have accumulated rights in period $\mathrm{t}-1$.

If the government were to decide that the reduced contributions under the unfunded scheme are replaced by contributions to a funded pillar, the legacy costs would be simply renamed as the transition costs of such a reform.

\section{Eliminating an inherited deficit of the pension plan}

As a next step we consider the elimination of an inherited imbalance in period t-1 and investigate the policy options and implications in period $t$ or beyond.

We first assume that the imbalance is constant (say a half of expenditure) and would exist in all future periods. Under these assumptions the actuarial deficit of the pension scheme is infinite if measured across all future generation. The actuarial deficit for all generations that have already contributed to the scheme is finite and amounts to $b_{t} N_{t-2} / 2+b_{t+1} N_{t-1} / 4$ at the beginning of period $t$.

As regards the size of implicit pension debt that is to be reduced (and hence the legacy costs to be financed), this depends on the commitment the government wants to honor. If the government wants 
to honor the committed benefit level (independent of how much own contributions this reflects) it is equal to the time period actuarial deficit $b_{t} \mathrm{~N}_{\mathrm{t}-2} / 2+\mathrm{b}_{\mathrm{t}+1} \mathrm{~N}_{\mathrm{t}-1} / 4$. If the government wants only to honor the commitment based on own contributions it is less (and in our case 50 percent).

$\begin{array}{lllll} & t-1 & t & t+1 & t+2 \\ R^{0} & b_{t-1} N_{t-3} & b_{t} N_{t-2} & b_{t+1} N_{t-1} & b_{t+2} N_{t} \\ R^{y} & c w_{t-1}^{o} N_{t-2} & c w^{\circ} N_{t-1} & c w^{0}{ }_{t+1} N_{t} & c w^{o}{ }_{t+2} N_{t+1} \\ B & c w^{y}{ }_{t-1} N_{t-1} & c w^{y} N_{t} & c w^{v}{ }_{t+1} N_{t+1} & c w^{o}{ }_{t+2} N_{t+1} \\ & -\left(b_{t-1} N_{t-3}\right) / 2 & -\left(b_{t} N_{t-2}\right) / 2 & -\left(b_{t+1} N_{t-1}\right) / 2 & -\left(b_{t+1} N_{t}\right) / 2\end{array}$

Under such settings the elimination of the deficit for period $t$ and beyond is limited to three key options:

(i) A reform that cuts the benefit levels that are out of sync with the level of contribution rates by 50 percent. This can be done by reneging the benefits for individuals of generation $\mathrm{N}_{\mathrm{t}-2}$ when they retire in period $t$ without possibilities to prepare for reduction through more own saving, and partially renege for generation $\mathrm{N}_{\mathrm{t}-1}$ that retires in period $\mathrm{t}+1$ as they have the opportunity as the generation of older workers in period t to compensate for the lower future benefit level. In this case no legacy costs were to emerge of this reform and the burden would fall on the pensioner generations of period $t$ and $t+1$.

(ii) A reform that cuts the future benefit level by 50 percent but shelters the generation of pensioners in period $t$ and $t+1$. Only as of period $t+2$ would the reform fully take hold. In this case it is the generation of workers in period $t$ and $t+1$ would already have their benefits aligned with their contribution efforts (incl. from employers). In this case the deficit sequence would be $-(\mathrm{btNt}-2) / 2,-(\mathrm{bt}+1 \mathrm{Nt}-1) / 4$ and 0 for the periods $t, t+1$ and $t+2$, respectively, and this would be equal to the legacy costs the government would have to finance. The legacy costs are cheaper than the present value of the deficits for these periods.

(iii) A third option of putting the scheme on fiscal balance consist in doubling the contribution rate for the workers as of period t while keeping the benefit level as before. In such an approach there would be no legacy costs; they would be paid by the current generation of workers while all current and future workers would have their future pensions aligned with their contributions

\section{Eliminating an inherited deficit of the pension plan and moving to lower benefit levels}

Most pension reforms constitute a mixture of addressing both an inherited deficit as well as moving to a benefit and contribution level that is more sustainable. This can be conceptualized in our model above as a temporary deficit resulting from too high promises and benefits to the generation t- 2 and $\mathrm{t}-1$ with no further future deficits from period $t+2$ onward as the benefit level would be reduced. In this case the government can pay the deficits for period $t$ and $t+1$ (i.e. pay for the legacy costs or actuarial deficit) or have high contribution rates for the working generations in period $t$ and $t+1$ that will not translated into higher benefits. If the labor supply is not fixed (as in our model), this is likely to create labor market distortions with lower levels of overall and formal employment. 


\section{Summing-up}

Assessing the fiscal implications of pension reform in our simple 3 generation OLG model brings a number of simple but important conclusions. They may not come as a surprise and should help in the next steps of conceptualizing the legacy costs:

First, the elimination of a permanent deficit of a pension scheme (unsustainability) needs to be dealt with through a reform, with measures on the revenue and/or expenditure side. As the system is reformed, securing the acquired rights (expected benefits) of current retirees and contributors leaves a transitory deficit (legacy costs) that is, however, much smaller than keeping an unreformed scheme; the actuarial deficit of the unreformed system may be infinite.

Second, for a shift from an NDB scheme to an NDC scheme with a fixed and long-term-sustainable contribution rate the legacy costs amounts to the actuarial post-reform deficit, is equivalent to the reduction of the implicit pension debt, and is finite. The two key sources of the legacy costs are the inherited legacy costs reflecting prior reforms and benefits above the steady-state under the old scheme, and reform-induced new legacy costs due to the shift toward a lower sustainable contribution rate;

Third, the elimination of a temporary deficit (as the result of too much generosity towards prior generations) can be done by reducing the acquired rights (e.g. for expected benefits that may not be based on equivalent contributions), burdening the working generation (with higher contributions) or paying for the deficit with general revenues. Burdening the working generation through higher contributions instead of paying the transitory deficit out of general revenues does not change the overall fiscal requirement but may be more costly for society once labor supply and demand is endogenized.

Forth, reducing further benefit and contribution levels in a sustainable scheme leads also to an additional transitory deficits and their actuarial value is equivalent to the reduction in the acquired right/accrued-to-date liability. While the overall amount is fixed, the time path of the deficit will depend of the speed of transition that ranges from new entrants to the labor market to all current workers. These legacy costs are equivalent to those known when moving toward a funded system (see Holzmann, 1998 and 1999).

\section{ii. Legacy Costs in a Macroeconomic Accounting Framework}

Pension reforms typically try to address a multitude of issues simultaneously such as handling the financing of high acquired rights of prior generations, bringing different schemes into one system, and reducing the future benefit (and contribution) level of a more harmonized system. Each of them contributes to an overall transitory deficit that differs from the aggregated base-line deficits of the unreformed schemes. The difference between both actuarial deficits is not the overall legacy costs but an amalgam that may or may not lead to a useful interpretation. If the present value of deficits over the next, say, 50 or 75 years are calculated (as proxy of the respective actuarial deficits) and pre-reform and reform values compared, this gives a useful indication about the overall fiscal savings, but not about the legacy costs that should, perhaps, be financed by general revenues.

However, doing such multiple reforms within an NDC framework has the objective of putting the system on a long-term financially sustainable basis and hence making the actuarial deficit finite. Furthermore, as no other revenues are available than contributions this very actuarial deficit of the reform scheme constitutes the (aggregate) legacy costs that need to be financed. Analytically, the sources of the legacy costs can be differentiated depending on the scope of reform such as: 
- Any acquired and honored rights of current retirees and contributors reflecting leftovers of prior reforms that have not previously been addressed through explicit legacy financing - hence surpassing the steady-state benefit level of the current system. Such old legacy costs exist in any case but were typically contribution and rarely general revenue financed.

- The acquired and honored rights of current retirees and contributors in excess of the sustainable benefits under the new contribution rate. These are new legacy costs that result from the transition from the old to the new and lower contribution rate equivalent to the (partial) move from an unfunded to a funded system. Hence the scope of these legacy costs are a political decision by how much the contribution rate and future benefits should be downward adjusted.

- The acquired, honored and perhaps, non-contributory rights of additional groups brought into the NDC scheme (such as civil servants). Such rights are already in the system and do not reflect new financial engagements as they would have to be financed in any case. But their inclusion makes these costs explicit. As the benefits of such groups have typically been higher than the future NDC benefits provided, the overall fiscal costs are likely eventually reduced. ${ }^{4}$

These components of the legacy costs can be individually estimated and should provide useful information: ex-ante for reform design and ex-post for the magnitude of gross versus net fiscal costs. In order to do so requires an actuarially-based projection model, discussed below.

What we propose and present here is a more aggregate approach that is directly based on the move toward a (perhaps harmonized) NDC scheme of a country. Such a calculation is based on the following components that need to be individually estimated and is based on the following equilibrium condition for an NDC (or any unfunded or funded pension) scheme.

[4] $\quad K_{t}+P_{t}=L_{t} \leq A_{t}=F A_{t}+P A_{t}+L C_{t}$

The left-hand side of [4] is the liability of the reformed pension system on day one $-L_{t}$ - and differentiates between the two key components: the liability toward current working generation and that toward the already retired. The latter $-P_{t}$ - easily calculated as the present value of benefits in disbursement; while respecting the rights of existing retirees with the reform the value may reflect changes in indexation rules through the reform. The liability toward the current generation - $\mathrm{K}_{\mathrm{t}}-$ reflects their accrued rights and in the case of an NDC system the aggregate value of the individual accounts. At the beginning of the reformed system these account values reflect the initial capital that has been recorded and is derived from a calculation that transformed acquired future rights of the unreformed system into an "equivalent" monetary amount in the reformed system.

The right-hand side reflects the assets side of the reformed pension system on day one $-A_{t}-$ and differentiates between the three key components: The financial asset that the scheme has inherited $\mathrm{FA}_{\mathrm{t}}$. In most cases this may be small or zero; in some cases (such as in Sweden) amounting to a major share of GDP inherited from the pre-reform scheme. The Pay-as-you-go asset of the pension scheme $\mathrm{PA}_{t}$ - defined and estimated as the present value of future contributions minus the present value of the corresponding benefits (see Prieto-Valdez, 2005). If the future scheme were to be perfectly actuarially fair, the PAYG asset would be zero (and all liabilities would need to be covered by the financial assets). Hence any positive value results from giving the future beneficiary a lower remuneration on their accounts than derived under a funded system. The assumed underlying positive difference between funded and unfunded rate of return (i.e. $r \geq g+n$ ) is akin to a tax and creates the PAYG assets. The last asset and hence the residual is the legacy cost $-L C_{t}$. Without such an asset (and the financing by

${ }^{4}$ The lower future benefits of these new groups of participants may come at a certain cost. If participants are fully or partially compensated by supplementary occupational schemes, additional future outlays will emerge for the plan sponsors and need to be taken into account. 
general revenue), the system would need to adjust the liability side to respect the equilibrium condition (4).

This (residual) definition of legacy costs can be used very handily to compare the changes in the components in equation (4) before and after the reform, at the time of starting the reform:

[5] $\quad \Delta \mathrm{LC}_{\mathrm{t}} \geq \Delta \mathrm{K}_{\mathrm{t}}+\Delta \mathrm{P}_{\mathrm{t}}-\Delta \mathrm{PA} \mathrm{A}_{\mathrm{t}}-\Delta \mathrm{FA} \mathrm{A}_{\mathrm{t}}$

While each of the four components on the right of the equation may change, the financial assets are quite likely to remain unchanged as a direct result of the reform (i.e. $\Delta \mathrm{FA}=0$ ). A second component that is likely to exhibit little change concerns the present value of benefits to existing retirees, albeit the reform may introduce changes such as modified indexation, e.g. moving from mixed wage-price indexation to mere price indexation (i.e. $\Delta \mathrm{P}_{\mathrm{t}} \leq 0$ ). The third component is more likely to display some changes. It represents the present value of accrued rights of the working generation. While an actuarial translation of the acquired rights should keep them unchanged, their often not fully defined nature and the strategic choice of a discount rate may allow for some reform gains (and hence $\Delta \mathrm{K}_{\mathrm{t}}<0$ ). Last but not least, the PAYG asset as the fourth component has the highest probability of change and exerts most influence on the size of the legacy costs (except, perhaps, the existing legacy costs of the unreformed system - $\mathrm{LC}_{\mathrm{t}}^{\mathrm{u}}$ ). For the PAYG asset both size and sign need to be assessed. The unreformed scheme may exhibit a low (or even highly negative) PAYG asset if the scheme was fiscally unsustainable (e.g. providing a rate of return in excess of the sustainable IRR) resulting in implicit financial liabilities. Moving it to an NDC scheme under the prevalent contribution rate makes the scheme financially sound for new contributors, and the PAYG asset and its change positive and large - thus contributing to a reduction of the legacy cost. This change in the PAYG asset eliminates any existing implicit financial liability of the old scheme for future generations but will still leave old legacy costs. If, in addition the system moves toward a lower contribution and benefit level, the tax base for financing the liabilities are reduced (even if the new system is in fiscal balance) and this increases the legacy costs. The stronger the reduction, the higher in absolute terms will $\triangle \mathrm{PA} t$ be if the level of contributors remain unchanged. However, the reduction in the contribution rate and the alignment with future benefit levels are expected to increase coverage, and the overall effect may be very strong in countries where coverage has been low. This may not only compensate for part of the negative change, but may actually create a negative legacy costs (reserve), discussed below. Finally, expression (5) covers only the change in the legacy costs to the unreformed scheme. Hence, for the full costs at the beginning of reform the legacy costs of the unreformed system need to be added $-\mathrm{LC}^{\mathrm{u}}{ }_{\mathrm{t}}$. As the permanent elements of unsustainability are addressed by the change in PAYG asset, it includes only the temporary elements of unsustainability, i.e. the inherited legacy costs of prior reforms that were not properly addressed. To illustrate the considerations above, Chart 1 to 4 present examples of the changes in the balance sheet of the pension scheme before and after reform: The origins and the resulting legacy costs.

The total costs to be financed are summarized in equation (6)

[6] $\quad \mathrm{LC}_{\mathrm{t}}=\mathrm{LC}_{\mathrm{t}}^{\mathrm{u}}+\Delta \mathrm{LC}_{\mathrm{t}}$

Equation [5] and [6] substantiate the starting definition of legacy cost based on the introspections of the OLG model that highlighted the basic cases that need to be differentiated. With this background we can move toward a measurement of these costs. The discussion made also clear that the concept and definition of legacy costs for an NDC reform do not differ materially from that of a (parametric) NDB reform, or any other pension reform applied to a funded or unfunded system, DB or DC. What will change are the size and sometimes sign of the different components. 
Chart 1: Balance Sheet: No Legacy Costs Unreformed Scheme

Liabilities

\begin{tabular}{|l|}
\hline Acquired \\
Rights: AR \\
\hline Pensions: P \\
\hline
\end{tabular}

Assets

\begin{tabular}{|l|}
\hline Financial \\
Assets: FA \\
\hline PAYG Asset: \\
PA \\
\hline
\end{tabular}

Reformed (NDC) Scheme

Liabilities

Assets

\begin{tabular}{|l|}
\hline Initial \\
Capital: $\mathrm{K}$ \\
\\
\hline Pensions: $\mathrm{P}$ \\
\hline
\end{tabular}

Financial

Assets: FA

PAYG Asset:

PA

$$
L C=0
$$

Chart 2: Balance Sheet: Inherited Legacy Costs Unreformed Scheme

Liabilities

\begin{tabular}{|l|}
\hline Acquired \\
Rights: AR \\
\hline Pensions: P \\
\hline
\end{tabular}

Assets

\begin{tabular}{l}
\hline Financial \\
Assets: FA \\
PAYG Asset: \\
PA \\
Implicit fin...... \\
liability \\
\hline
\end{tabular}

Reformed (NDC) Scheme

Liabilities

Assets

\begin{tabular}{|l|}
\hline $\begin{array}{l}\text { Initial } \\
\text { Capital: } \mathrm{K}\end{array}$ \\
\hline Pensions: $\mathrm{P}$ \\
\hline
\end{tabular}

Financial

Assets: FA

PAYG Asset:

PA

Legacy costs

$$
\mathbf{L C}=\mathbf{L C}^{\mathrm{u}}
$$

Chart 3: Balance Sheet: Reform-created Legacy Costs

Unreformed Scheme

Liabilities

\begin{tabular}{l}
\hline Acquired \\
Rights: AR \\
\hline Pensions: P \\
\hline
\end{tabular}

Assets

\begin{tabular}{l}
\hline Financial \\
Assets: FA \\
PAYG Asset: \\
PA \\
\end{tabular}

Reformed (NDC) Scheme

Liabilities

\begin{tabular}{l}
\hline Initial \\
Capital: $\mathrm{K}$ \\
\\
Pensions.................. \\
\hline
\end{tabular}

Assets

\begin{tabular}{|l|}
\hline Financial \\
Assets: FA \\
PAYG Asset: \\
PA \\
Legacy costs \\
\hline
\end{tabular}

$$
L C=-\Delta P A
$$

Chart 4: Balance Sheet: Inherited and Reform-created Legacy Costs Unreformed Scheme

Liabilities

\begin{tabular}{|l|}
\hline Acquired \\
Rights: AR \\
\hline Pensions: P \\
\hline
\end{tabular}

Assets

\begin{tabular}{|l|}
\hline Financial \\
Assets: FA \\
PAYG Asset: \\
PA \\
\hline Implicicion fin. \\
liability \\
\hline
\end{tabular}

Reformed (NDC) Scheme

Liabilities

\begin{tabular}{l}
\hline Initial \\
Capital: $\mathrm{K}$ \\
\\
Pensions: $\mathrm{P}$ \\
\end{tabular}

Assets

Financial Assets: FA PAYG Asset: PA Legacy costs

$$
\mathrm{LC}=\mathrm{LC}^{\mathrm{u}}+\Delta \mathrm{PA}
$$




\section{How to Measure Legacy Costs?}

The best approach, in principle, to measure the legacy costs of a pension system is to use actuarial methods to estimate of the financing gaps (tax overhang) for the new and reformed system both as overall amount as well as the time path of financing requirements. While such an approach has methodological merits, it also has a number of drawbacks and raises a number of conditions that may not be easily met (e.g. on data) in low and middle income countries. For this reason other and more rule-of-the-thumb methods will be discussed that should allow getting first magnitudes before venturing in more sophisticated methods.

\section{Actuarial methods: Benefits and challenges}

Actuarial methods are the best approach for measuring the legacy costs and should be undertaken, when possible. However, in order to do them well poses major requirements as well as conceptual and political issues for which we do not always have good solutions. More specifically:

An actuary can calculate everything, given a price and quantity structure. In reality, however, a number of these data are not known and need to be approximated. Equally important, the concept of actuarial studies is more easily applied to company schemes and requires in the case of country-wide schemes the introduction of macro-economic considerations to render the assumptions consistent. A special challenge for country-wide schemes poses the selection of the appropriate interest to be applied for discounting. While the use of the term-structure of government bonds may be a valid approach, only in the most developed countries with a full-blown financial market are bond interest rate term-structure for 30 years available. And even if they are available their use may not be fully embraced as they do not necessarily reflect all future information but current conditions of fiscal and monetary policy. For this and other reasons a number of economists propose to use the projected GDP growth rate (with our without a mark-up of, say 100,150 or $200 \mathrm{bp}$ ) as a more appropriate and pragmatic approach-a proposal that is typically not shared by actuaries.

A related issue concerns the existing actuarial capacity in countries that is often weak. Calling in foreign experts to undertake the actuarial work is possible but typically quite expensive and the results may not have the same buy-in, also because the external experts may be considered less able to model the intricacies of the old and reformed system. Also, countries are typically engaging in adjustments to the reform once they see the price tag, changing the actuarial (fiscal) outcome without a re-estimation undertaken. For this reason the World Bank has developed some time ago the Pension Reform Options Simulation Toolkit (PROST) and trained government officials in its application. While not an actuarial model it is fully consistent with actuarial methods, allows more flexibility with regard to lacking data and assumptions in a transparent manner, and offers ways to assure macroeconomic consistency of parameter assumptions. It does not have (yet) a module for legacy costs but both the overall amount as well as the time path of these costs can be easily calculated.

All estimation models are confronted with political gaming that results from data provided by social security institutions and this issue gets very protracted in a decentralized setting. As such institutions have an interest to maximize the estimated legacy costs as they define the future public transfer to the reformed system, the supplied data and information may be biased without the capacity for direct verification. This makes the use of simpler and rule-of-the-thump methods even more important. 


\section{Rule-of-the-thumb methods}

The essentials of rule-of-the-thumb methods are three-fold: use of to established quantitative relations between pension aggregates (e.g. between stocks and flows), use of quantitative information about individual aggregates (e.g. cost-covering contribution rate), and combination of information and cross checking (or best triangulation of estimate). As it must have become clear - we are moving from science to art.

As a starting point we can use expression [7] that combines equation [4] to [6] and expresses the legacy costs of the reformed system as that of the unreformed scheme plus the identified elements of change brought about by the reform. Which side of the identity is used is determined by available information and considerations such as the maturity of the unreformed system.

$$
\mathrm{LC}_{\mathrm{t}}^{\mathrm{r}}=\mathrm{K}_{\mathrm{t}}^{\mathrm{r}}+\mathrm{P}_{\mathrm{t}}^{\mathrm{r}}-\mathrm{PA}_{\mathrm{t}}^{\mathrm{r}}-\mathrm{FA}_{\mathrm{t}}^{\mathrm{r}}=\mathrm{LC}_{\mathrm{t}}^{\mathrm{u}}+\Delta \mathrm{LC}_{\mathrm{t}}=\mathrm{LC}_{\mathrm{t}}^{\mathrm{u}}+\Delta \mathrm{K}_{\mathrm{t}}+\Delta \mathrm{P}_{\mathrm{t}}-\Delta \mathrm{PA}_{\mathrm{t}}-\Delta \mathrm{FA}_{\mathrm{t}}
$$

A reform that fully honors acquired rights makes $\Delta P$ and $\Delta K$ equal to zero, and a reform should also not change the financial assets (e.i. $\Delta F A=0$ ). This simplifies equation [7] to

$$
\text { [7]' } \quad \mathrm{LC}=\mathrm{LC}^{\mathrm{u}}+\Delta \mathrm{LC}=\mathrm{LC}^{\mathrm{u}}-\triangle \mathrm{PA}
$$

The inherited legacy costs $L C^{u}$ reflect the current cost-covering contribution rate $C R^{u}$ in excess of the steady-state contribution rate $\mathrm{CR}^{\text {su }}$ of the unreformed scheme, and the change in the contribution asset $\triangle P A$ reflects the reduction of the contribution rate from this steady-state level to the new and politically determined steady state level $\mathrm{CR}^{r}$. Both old legacy costs and reform-induced legacy costs, and their sum, can be presented in terms of the implicit pension debt (ignoring financial assets and making use [4] i.e. that liabilities are the measured implicit pension debt - IPD - and are equivalent to PA plus LC). This gives us easy estimators for total legacy costs, the inherited legacy costs, and the reform induced legacy costs, respectively:

$$
\begin{array}{lll}
\text { Total legacy costs : } & {[8 \mathrm{a}]} & \mathrm{IPD}^{\mathrm{u}}\left(\mathrm{CR}^{\mathrm{u}}-\mathrm{CR}^{\mathrm{r}}\right) / \mathrm{CR}^{\mathrm{u}} \\
\text { Inherited legacy costs : } & {[8 b]} & \mathrm{IPD}^{\mathrm{u}}\left(\mathrm{CR}^{\mathrm{u}}-\mathrm{CR}^{\mathrm{su}}\right) / \mathrm{CR}^{\mathrm{u}} \\
\text { Reform-induced legacy costs: } & {[8 \mathrm{c}]} & \mathrm{IPD}^{\mathrm{u}}\left(\mathrm{CR}^{\mathrm{su}}-\mathrm{CR}^{\mathrm{r}}\right) / \mathrm{CR}^{\mathrm{u}}
\end{array}
$$

Here are a few examples of how to questimate the legacy costs.

\section{Examples:}

Countries often have estimates (even it at times dated) of the accrued-to-date liability, perhaps differentiated between that for active population and pensioners (i.e. $\mathrm{K}_{\mathrm{t}}^{\mathrm{u}}+\mathrm{P}_{\mathrm{t}}^{\mathrm{u}}$ ). Expressed in percent of GDP even dated estimates can be used as a starting point to estimate the magnitudes for the reformed scheme.

Let's assume the estimated IPD is 180 percent of GDP that is currently financed by a contribution rate of 32 percent while the long-term sustainable rate is 24 percent. Hence we have an inherited legacy costs of $180 \times(32-24) / 24$ or 60 percent of GDP. If the reform sets the new contribution rate at 20 percent, this creates a reform induced legacy cost is derived from the new sustainable IPD of $120 *(24-20) / 24$ or 20 percent of GDP. Hence the total legacy costs - inherited and reform induced amount to 80 percent of GDP.

If the reform does not honor all of the acquired rights but changes, say, the indexation from wage to price indexation this reduces the inherited pension debt (as the value of $\mathrm{K}_{\mathrm{t}}$ and $\mathrm{P}_{\mathrm{t}}$ is reduced as they have been calculated at full wage indexation). It may or may not also increase the PAYG asset depending if in the new scheme lower indexation is compensated by higher initial pension. The magnitudes of a change in indexation are important. E.g. for an assumed real wage growth of 2 percent 
a change to pure priced indexation amounts to about $1 / 6$ of IPD (Holzmann, 1998). If applied to current and future retirees this some 30 percent of GDP (for an IPD of 180 percent).

If there are no estimates for the accrued to date liability, a stock-flow relationship can be used to establish a broad estimate. Empirical estimates put the ratio of accrued-to-date liability to current (annual) pension expenditure in the range of 20 to 30 (see Holzmann 1998, Table 2). This range reflects also differences in the applied discount rates typically assumed above annual GPD or wage growth. Assuming no difference between discount rate and GDP growth puts the ratio towards and above the upper range and makes it equivalent to the turn-over duration. Mere demographically-based estimates for the turn-over duration put it into the range of 30 to 35 years (Settegren and Boguslaw, 2006, Annex 7D). A reasonable value is 30 . Of course, such an approach is only valid if the system is broadly mature. In an unmature system the ratio starts at infinity and approaches the steady-state value only gradually (Holzmann, Palacios, Zviniene, 2004, Table 7). In an unreformed system, the ratio is typically underestimated as the liabilities are not yet fully reflected into the flows that react more slowly; the reverse applies for a reformed system where the impact on stock is immediate but the flows change little in the short run.

\section{Cash profile of the legacy costs and speed of transition}

The estimated stock of legacy costs says little about the timing of the flows and hence of the financing needs of governments. The considerations so far have assumed an immediate transfer of all current workers (and retirees) to the new system. Hence, everybody from the new system entrant to the person one day before retirement would have his or her acquired rights transformed into a notional (initial) capital and continue the next day with the recording of contributions (with reduced contribution rates) on his or her individual account. Such a full immediate transition puts the highest cash-flow needs up front and concentrated on the next 40 years or so (unless coverage expansion takes place). It starts out with the difference between the broadly unchanged pension expenditure minus the revenues under the new and fixed contribution rate, with the reduction happening in an S-shaped curvature for many years.

The cash-flow needs for a more gradual transition for current workers would kick in also more gradually but the overall legacy cost would not necessarily be smaller; on the contrary. But it depends on the starting conditions and how the transition is staged.

- If the conversion to the new scheme concerns only the younger workers, say below age 40, while the older workers continue under the old system, the immediate cash flow is smaller but increasing until all workers are in the new scheme (say in 20 years, if the retirement age is 60). The overall legacy costs would remain unchanged if the reform would merely mean a move from an actuarially sound system with a high to one with a lower contribution rate. If the system was financially unsound to start with, the older workers under the old system would continue to acquire benefits beyond their contribution efforts and the overall legacy costs would increase.

- If the conversion to the new scheme concerns only the new entrants while everybody already in the old system would continue to stay there, the cash flow needs would increase for the next 40 or so years and gradually be reduced thereafter for other 40 years. Again, the overall legacy costs would remain unchanged if the reform would merely mean a move from an actuarially sound system with a high to one with a lower contribution rate. If the system was financially unsound to start with, as all the older workers under the old system would continue to acquire benefits beyond their contribution efforts and the overall legacy costs would increase and have its highest value. It would be composed of the transition costs of moving from a high to a lower contribution rate equivalent to 
the move from an unfunded to a funded system plus the accrued costs of un-sustainability for longest time.

As most NDC reforms are likely to comprise both a move toward a lower contribution rate as well as rendering a financially unsound system sustainable, the message is clear: Do a reform as quickly as possible and move everybody at once to the new system.

\section{Financing of legacy costs}

There are essentially three ways to finance the legacy costs of a (NDC) pension reform: (i) reducing the size of the costs by reneging on some of the existing commitments (i.e. burdening the generations of current retirees and those soon to retire),

(ii) reducing the size of the costs by increasing the value of the PAYG asset by coverage expansion (for a given new contribution rate), and

(iii) the residual strategy consists of the use of general government revenues to finance the legacy costs with the understanding that these resources need to be levied in a less distortionary manner than contribution financing.

In addition to these considerations about the type of financing, and their magnitudes, it is important for real-life reforms to understand also the timing, sequence and disbursement of the needed general government revenues. These aspects will be also highlighted from issues emerging under the ongoing Chinese pension reform discussion.

\section{Reneging on existing commitments}

The options for reneging on legacy costs under an NDC reform are, perhaps, more limited than under a parametric reform but not zero. In both cases the reneging options for pensions under payment are largely limited to changing the benefit indexation, and for both current and future retirees the move toward a more consistent tax treatment can raise additional revenues. For current workers under an NDC reform the partial reneging seems to be limited to various technical assumptions during the calculation of the initial capital, as well as parametric increases in the retirement age.

Moving from wage or mixed wage-price indexation toward mere price indexation is a powerful instrument to reduce legacy costs. As outline above, a move from wage to price indexation under an assumed real wage growth of 2 percent per annum shaves-off some 1/6 of an accrued-to-date liability and hence is a sizable contribution to financing of the legacy costs. Furthermore, such a change in indexation is essentially a reduction of existing commitments and may have no material impact on the retirees under the new system. In an NDC system that lives fully within its means, the choice of indexation (price, mixed, or wages) is always done in trading-off to an adjustments in the initially accorded pension. In case of planned full wage instead of mere price indexation, the notional interest rate and in consequence the account values are adjusted downward to accommodate the back-loading of benefit expenditure.

Many countries across the world provide tax advantages for their pension system beyond consumptiontype taxation. In numerous countries individuals escape taxation at every stage (contribution, accumulation and disbursement) and hence introducing consistent taxation (of EET or TEE) would already create sizeable revenues to co-finance any legacy costs of reform.

A potentially powerful approach to reduce much of the legacy costs of an NDC reform would consist in first undertaking a parametric reform that increases retirement age and reduces (defined) benefits through lower annual accrual rates, lengthening of assessment periods, etc. before converting the reduced acquired rights into an initial capital under an NDC reform. While conceptually possible, the 
political economy may speak against such an approach. Parametric reforms have proven difficult to undertake, inter alia as they lack credibility. The attraction of an NDC reform is, inter alia, the promise to honor acquired rights while putting the scheme on a financially sustainable basis. Yet, this very promise leads to higher legacy costs that need to be addressed.

In a NDC system the retirement age should become an endogenous variable as individuals are assumed to react to initial reduction in benefits (as a result of the NDC system introduction and the move toward lower contribution rates) and future benefit reductions (as a result of increases in life-expectancy) with delays in retirement under the quasi-actuarial benefit structure. However, fiscal as well as meritocratic considerations speak in favor of a more proactive approach in increasing the retirement age. For fiscal reasons, an increase in the standard retirement age to say 65 (and above) should be announced and scheduled prior to the NDC reform. Against this new benchmark the acquired benefit rights would be calculated leading to a fall in their present values. For the NDC system itself many experts argue for a minimum retirement age that is indexed to changes in life expectancy and requests a minimum balance able to finance a benefit well in excess of a guaranteed minimum retirement income.

Last but not least, the calculation of the initial capital that converts acquired rights into notional amounts recorded in the individual accounts can be used tacitly to reduce the legacy costs. The two key instruments are the choice of the discount rate in case projected future benefits under the old system are converted into notional capital, and the selection of the lower costs between such a discounting (top-down) approach and an revaluation (bottom-up) approach in which past contributions are revalued with historic and sustainable notional interest rates (Palmer 2006). The data and calculation demands for the latter approach are challenging but worthwhile to consider.

\section{Increasing the value of the contribution asset by coverage increase}

A critical contribution to the financing of the legacy costs (and the building of the reserve fund) can be expected from an increase in coverage, in particular in (developing) countries that start out with a low share of labor force in the formal sector and hence contributing to the (unreformed) scheme. Freeing the contribution rate in the reformed scheme from the legacy costs should create a first incentive for fostered formal labor force participation; having a very close contribution/benefit link should create a second incentive for system participation; having a scheme that promises financial sustainability and the creation of a reserve fund that promises solvency should muster credibility that in turn should create another incentive for system participation.

The size and timing of a coverage-determined increase in the contribution asset for the financing of the legacy costs will not only depend on improved incentives to system participation but perhaps equally (or more importantly) on reform-related other improvements such as in communication, administration, and contribution collection. While empirically system coverage of countries remains closely linked to economic development (measured by country GDP/capita), the link is far from perfect and differences across countries for a given per capita income signal a strong influence of the latter. But it also signals that coverage expansion will be the strongest where pension reform, strong economic development, and administrative efforts coincide.

A simple modeling exercise indicates that coverage increase may, indeed, contribute to the financing of legacy costs in a major way. Let's assume that the unreformed system has an accrued to date liability of 120 percent of GDP and related expenditures of 4 percent of GDP, the reformed NDC scheme steady state expenditure of 3 percent (prior to coverage expansion) as the contribution rate is reduced from, say, 20 to 15 percent and hence imply reform-induced legacy costs of 30 percent of GDP, and the original coverage rate of labor force was 25 percent. In a first scenario exercise we assume no old legacy costs, only reform induced legacy costs due to contribution rate reduction. We investigated various 
degrees of coverage expansion between 0 (baseline) and $100 \%$ in steps of 25 percent. To this end we assume that the increase takes place over 40 years and the first benefit pay-outs for new participants start after 20 years

Chart 5 suggests that already modest increases in coverage are able to reduce the deficits and hence the legacy costs importantly. A 25 percent coverage increase over 40 years (hence from 25 to 31.25 percent of coverage of labor force) would eliminate the transition deficit after year 34 of the reform and stabilize the overall legacy costs at slightly above half of the baseline value; a 50 percent coverage increase would eliminate the deficit after 20 years and the surpluses thereafter would reduce the legacy costs to almost nil after another 30 years. Higher increases in coverage (75 and 100 percent, respectively) would create even stronger surpluses that could give rise to sizable reserve funds after some 50 years. A doubling of the coverage within 40 years from 25 to 50 percent of labor force seems possible if integrated into a broader and successful reform agenda.

For a second scenario exercise we add inherited legacy costs (from prior reforms) of 40 percent of GDP that are assumed to become expenditure over a period of 50 years in a decreasing (death-related) scale starting with 1.5 percent of GDP in year one of the reform. Chart 6 suggests that with such high inherited legacy costs the doubling of coverage will not be sufficient to pay for the legacy cost. However, assuming an increase by 150 percent (to 67.5 percent of labor force) would move the aggregated legacy costs well into surplus. A three folding of coverage to 75 percent would create sizable reserves - quite ambitious but not totally impossible.

These, perhaps optimistic, results will need to be substantiated and verified in a real-country setting using a fully-fledged and actuarially based projection model. However, we conjecture that such results will not differ too much from our modeling exercise.

General tax revenue financing has attracted increasing attention in the debate about pension reform, as well as more broadly social insurance reform. On net, any such shift only makes economic sense insofar as the marginal cost of raising additional public funds is lower when using other general tax instruments rather than the more conventional tool of social insurance contributions. Expressed differently, it is only useful to take this road insofar as the other tax instruments have lower financial and opportunity costs associated with them.

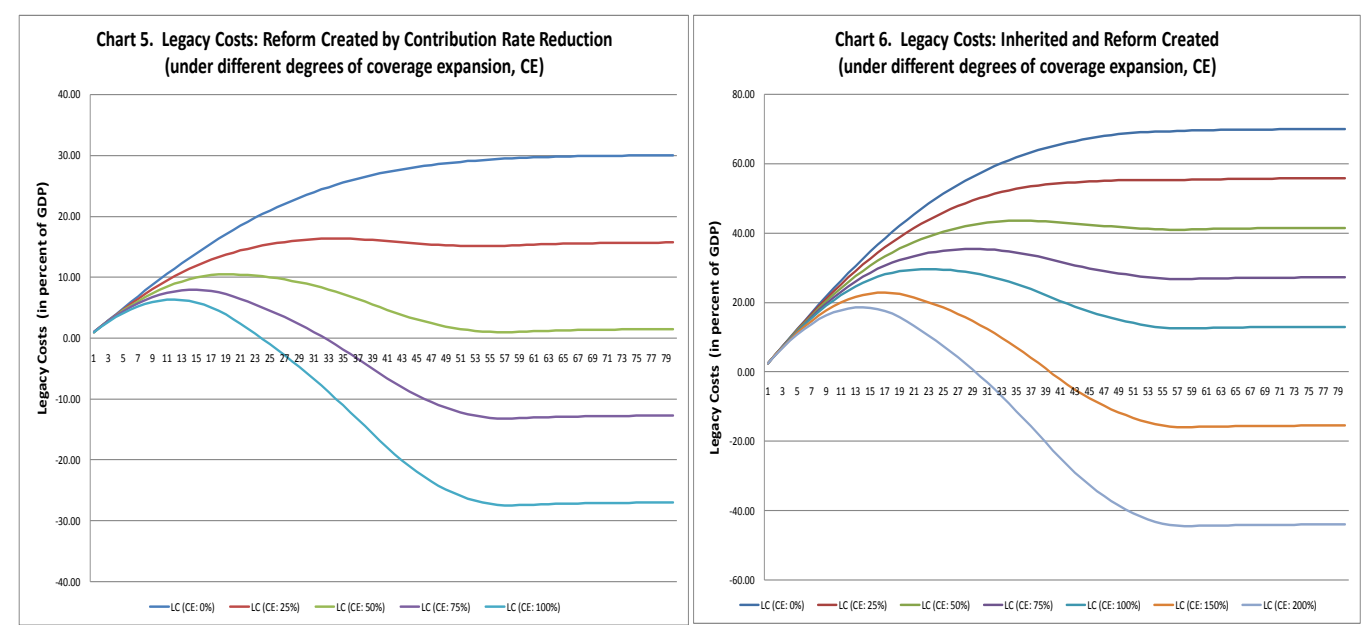

Source: Authors calculations 
Beyond pure collection costs, one key decision parameter is the economic distortion generated by the various tax instruments at the level of economic decision makers. An important theoretical, empirical and simulation-based literature has developed on this topic. Basic results of optimal tax theory-such as Atkinson and Stiglitz (1976)-point to the negative consequences of capital income taxation. The key logic is simple: by taxing capital income-be it under the form of corporate income taxes or (final) withholding taxes on dividends, etc-the government has an unfavorable influence on the allocation of resources, and thus the growth and size of the economy in the future.

Over the recent years, the IMF has contributed to the literature on financing the transition costs linked to population aging. It developed the IMF Global Fiscal Model-a dynamic macro-simulation model that allows for international interdependencies notably at the level of the capital markets. ${ }^{5}$ Generally, the results give simple lessons that are de facto the direct results of the neoclassical growth model underlying these dynamic systems: They underline the special role of capital taxation in the growth process. Indirect taxation is the most preferable tax instrument to use in the face of aging pressures, while wage taxation (i.e. social insurance contributions) are better than general income taxes or capital income taxes. On net, these-as well as other similar growth models-document that a shift toward consumption-based taxation away from income taxes reduces distortions of savings and labor supply decisions, and hence contributes to a larger "size of the pie" in the future. ${ }^{6}$

Furthermore, these authors point out the fact that consumption is a more stable tax base than any income concept purely on the basis of the larger degree of stability of the tax basis across the economic cycle. While such stability might be desirable, particularly when laying out the trajectory for a transition, it clearly has to be balanced against a lesser counter-cyclicality of the tax system, and hence a lesser role of the tax system as an automatic stabilizer in the economy.

One real-world implication is the increasing role of the VAT as a financing tool for public expenditures of all kinds, notably complementary social insurance financing. The evidence from macro-simulation models is actually further reinforced by observations on the ground showing that VAT has a relatively moderate economic cost relative to the revenues generated - be it because it does not affect savings or because the systems generally have an easier structure than most income tax systems. ${ }^{7}$ But these empirical observations also point to another important factor: the relative cost of raising public resources with different tax instruments heavily depends on the country specifics.

While these theoretical and simulation-based results are striking, the empirical literature on the effects of taxation on labor supply and savings has been much less unanimous. Well-known individual-level studies from the US as well as from other OECD countries show a few key empirical regularities of the labor market: labor income taxation has little effect on the labor supply of the primary income earner in a household, while the effect on secondary earners is mostly one of participation rather than of modified hours of work. Similarly, more recent evidence shows that this effect is much stronger for indigenous workers in their prime-years as compared to either people just out of school, close to

${ }^{5}$ Botman and Kumar (2007) and Botman and Tuladhar (2008) are just two examples of this approach.

${ }^{6}$ Diamond (2009) emphasizes the strong theoretical requirements for obtaining such clear preference relations over tax instruments. He notably emphasizes the role of heterogeneity between individuals, as well as the complicated interactions between year-based tax systems and life-time redistribution in the context of social security programs. His results further emphasize the point we previously mentioned, that intra-generational considerations play a crucial role in evaluating the desirability and the incidence of any pension system transition.

${ }^{7}$ It is generally recognized that a VAT system, in order to achieve its objectives of raising substantial revenues at moderate administrative and compliance cost, should have a simple design - with possibly only one positive rate combined with a very limited number of exemptions. Such a system would be accompanied by adequate public expenditure programs to address distributional issues whenever they arise. 
retirement, as well as from migration backgrounds. ${ }^{8}$ As for capital income taxation, the empirical evidence remains highly inconclusive-the main reason being the difficulty of appropriately measuring the relevant individual-level interest rate and savings parameters. ${ }^{9}$

Regarding developing countries, the empirical evidence is equally mixed. For example, Keen and Mansour (2009) highlight the increasing role of the VAT as a revenue source for sub-Saharan African countries over the last decades. This increase in VAT has however not necessarily generated new budgetary margins, as most countries have faced a sustained and structural fall in customs revenues as well as strong and increasing tax competition at the level of the corporate income tax. Going forward, the picture looks more challenging. In a number of developing countries, simple hikes of VAT rates are an increasingly unlikely policy tool, given the standard rates currently applied -in the developing world in a context of high degree of informality, scarce administrative capacity, and design flaws that limit effective operations and enforcement.

Policy-wise, these empirical aspects have several implications: First, in the context of developed countries with quasi-universal pension systems and sophisticated VAT systems, a general shift of the tax burden away from labor to consumption is likely to have smaller than expected efficiency gains, hence reducing the attractiveness of such a policy. ${ }^{10}$ For developing countries, there is an additional aspect: financing the transition of a pension system covering a moderate fraction of the population by a generally applicable (potentially dysfunctional) VAT could involve major inefficiency and undesired redistribution among households in the country. Furthermore, it might necessitate profound reforms of the VAT system itself to restore primary aim as a simple tool for non-distortive revenue generation.

\section{Sequencing and disbursement of needed general revenues}

The burden sharing arrangement over the different generations plays an important role in the design of the transition. Whenever legacy costs are explicitly recognized in the context of a reform, they appear as one-off amounts at the time of the reform even as they are disbursed over time. Benefits of the transition toward a reformed system, however, do accrue progressively over time to all the generations going forward.

This situation leads to a number of intertemporal considerations. Holzmann (1998) already recognized several concerns that would justify the temporary buildup of an explicit debt. These included intergenerational equity, as well as efficiency arguments based on intertemporal tax smoothing as well as incremental deadweight loss due to the inefficiency of existing tax/benefit systems. On the other hand, the absence of perfect equivalence between explicit and implicit debt, as well as negative externalities on the development of private (financial) markets as well as government financing costs would plea against a debt-financing of legacy costs with costs spread over different generations.

Another approach explored by Feldstein et al (2001) is to identify and isolate the legacy costs of the old system - but to keep the legacy costs implicit rather than convert them into an explicit amount. To study the consequences of their setting, they used a formal model of the US economy to simulate the partial shift towards a fully funded individual accounts system. By positioning their model in the context of uncertain returns and by imposing a constraint that any generation gets benefits that are at least as large as the baseline represented by current legislation, they show how a social welfare enhancing transition can be orchestrated by a rather modest complementary individual savings component-with

${ }^{8}$ E.g., Kramarz and Philippon (2001) as well as Chéron et al (2008) study tax and contribution policy in the face of labor market segmentation.

${ }^{9}$ See, e.g., Attanasio and Weber (1995).

${ }^{10}$ See the discussions on the desirability of a "social" VAT in France, as detailed in Besson (2007). 
the existing PAYG system used as a top-up scheme for the new individual accounts system. De facto, their model is a progressive social contributions-financed transition with the costs of the transition spread over a number of future generations.

\section{Giving Meat to the Bones: The Concepts Applied to a Hypothetical Chinese NDC Pension Reform}

Despite major and minor reforms of the Chinese pension system over recent decades it remains fragmented within and between the urban and rural areas, does not provide comprehensive basic means-tested benefits for the poor elderly and has no credible occupational/personal voluntary retirement saving scheme. The reformed urban system collects a high contribution rate (between 28 and 31 percent) to cover legacy costs, with the cost covering contribution rate estimated at 35 percent and the steady-state of the reformed scheme estimated at 27 percent (Sin 2005). There are separate schemes for public service units (PSU) and state organs (i.e. civil servants), and migrants are only very partially covered by separate schemes. For the rural area voluntary saving schemes with government subsidized contributions existed for some time and a new pilot of such a (voluntary) matching defined contribution scheme covering 10 percent of the counties has started in 2009.

The Chinese government is very much aware of the key shortcomings of the system. In preparation of the next five-year plan (2012-2017) the government has asked an (undisclosed) set of international institutions and academics to prepare their vision piece for a Chinese pension reform in order to fertilize the domestic Chinese reform discussion. The proposal to make an NDC system the core of the future pension scheme has been made by a number of contributions (e.g. Barr and Diamond 2009, Oksanen 2010, World Bank 2010, and Zheng 2010). A key element to make such a proposal credible is, of course, to have broad estimates of the legacy costs and a game-plan for their financing.

We present here the broad estimates that were undertaken in World Bank (2010) based on the rule-ofthumb methodology outlined above. It uses expenditures and a range of multipliers to estimate the implicit pension debt for the three schemes to be harmonized (urban scheme, public organ scheme, and public service unit scheme). A range of multiplies is needed as the Chinese pension scheme is not yet mature and well above the steady state multiplier of 30; the multiplier range has drawn on historical national and provincial estimates. For scenario calculations of the (new) and common contribution rate 15, 20 and 25 percent are selected. This compares with a cost covering contribution rate of the three unreformed schemes of 35, 36 and 34 percent, respectively. Applying the estimator for the legacy costs in equation [8a] provides the range of legacy cost estimates in the shaded area of Table 1 . The lower the selected new contribution rate the higher the legacy cost for a given estimated IPD.

Table 1: China: Broad Estimates of the Legacy Costs under an NDC reform and Alternative Contribution Rates for the New Scheme

\begin{tabular}{|c|c|c|c|c|c|c|c|c|c|c|}
\hline \multirow{3}{*}{$\begin{array}{l}\text { Estimates } 2008 \\
\text { in \% of GDP }\end{array}$} & \multicolumn{3}{|l|}{ Pen Exp } & Cost Covering & \multirow{2}{*}{\multicolumn{3}{|c|}{$\begin{array}{l}\text { Legacy costs (low IPD estimate) } \\
\text { New Contribution Rate }\end{array}$}} & \multirow{2}{*}{\multicolumn{3}{|c|}{$\begin{array}{l}\text { Legacy costs (high IPD estimate) } \\
\text { New Contribution Rate }\end{array}$}} \\
\hline & \multirow{2}{*}{\multicolumn{3}{|c|}{ low est. high est. }} & \multirow[t]{2}{*}{ - Cont. Rate \% } & & & & & & \\
\hline & & & & & $15 \%$ & $20 \%$ & $25 \%$ & $15 \%$ & $20 \%$ & $25 \%$ \\
\hline Urban system & 2.46 & 118 & 147 & $35 \%$ & 67 & 50 & 34 & 84 & 63 & 42 \\
\hline State organs & 0.34 & 12 & 16 & $36 \%$ & 7 & 5 & 4 & 9 & 7 & 5 \\
\hline PSU & 0.75 & 26 & 36 & $34 \%$ & 15 & 11 & 7 & 20 & 15 & 9 \\
\hline Total & 3.54 & 155 & 199 & & 89 & 66 & 44 & 113 & 85 & 56 \\
\hline
\end{tabular}

Source: World Bank (2010)

Given the scenario approach the resulting legacy costs differ widely depending on the IPD estimated and selected new steady-state contribution rate. The highest estimated for total legacy costs (due to the lowest new contribution rate of 15 percent) range between 89 and 133 percent of GDP and are 
distributed between the urban and the government sector schemes in the ratio of 3:1. From these total legacy costs a main share is inherited and needs to be financed in any case and much or all of the legacy costs for the newly integrated government sector schemes are already tax financed as contributions are not levied from state organs and only for a small share of the public sector unit employees. Altogether (and using an average of the calculated implicit pension debt of 150 percent) this leaves some 75 percent of GDP to be financed from additional general government or other means, most importantly coverage expansion in the private sector.

During the period of 1998 to 2008 coverage increased already 39.2 to 54.9 percent, i.e. 15.4 percentage points in the urban scheme. This has helped increase the reserves of the urban scheme from 0.7 to 3.3 percent of GDP, i.e. 2.6 percentage points. Achieving a coverage rate of 90 percent by 2050 seems possible and in line with international trends in the relationship between per capita income and coverage (see World Bank, 2006); it is also goal of the Chinese government. Furthermore, during the period 1998-2008 labor force increased already by almost 40 percent. Over the next 40 years labor force could easily double as the result of rural-urban migration (plus an increase in labor force participation). As a result of both effects the overall number of contributors could multifold and create cash flows to help finance the legacy costs.

Chart 7 provides stylized estimates for China of the net legacy costs (i.e. without government sector schemes) for different coverage expansion scenarios and 2 selected new contribution rates (15\% and $20 \%$ ). They are derived from a model that replicates the initial deficit and the estimates for the inherited legacy costs ( 30 percent of GDP) and reform-created legacy costs ( 45 percent of GDP under an assumed new contribution rate of 15 percent). It ignores demographic changes by assuming that they are neutralized by higher retirement age and/or lower benefits. The graph indicates that coverage expansion could, indeed, importantly contributed to the financing of the legacy costs to the tune of some 10 to 13 percent of GDP for an expansion of covered labor force of 50 percent over 40 years.

\section{Chart 7. Phasing of Net Legacy Costs \\ Under Different Degrees of Coverage Expansion (CE) and Contribution Rates (15\% - left - and $20 \%$ - right panel)}
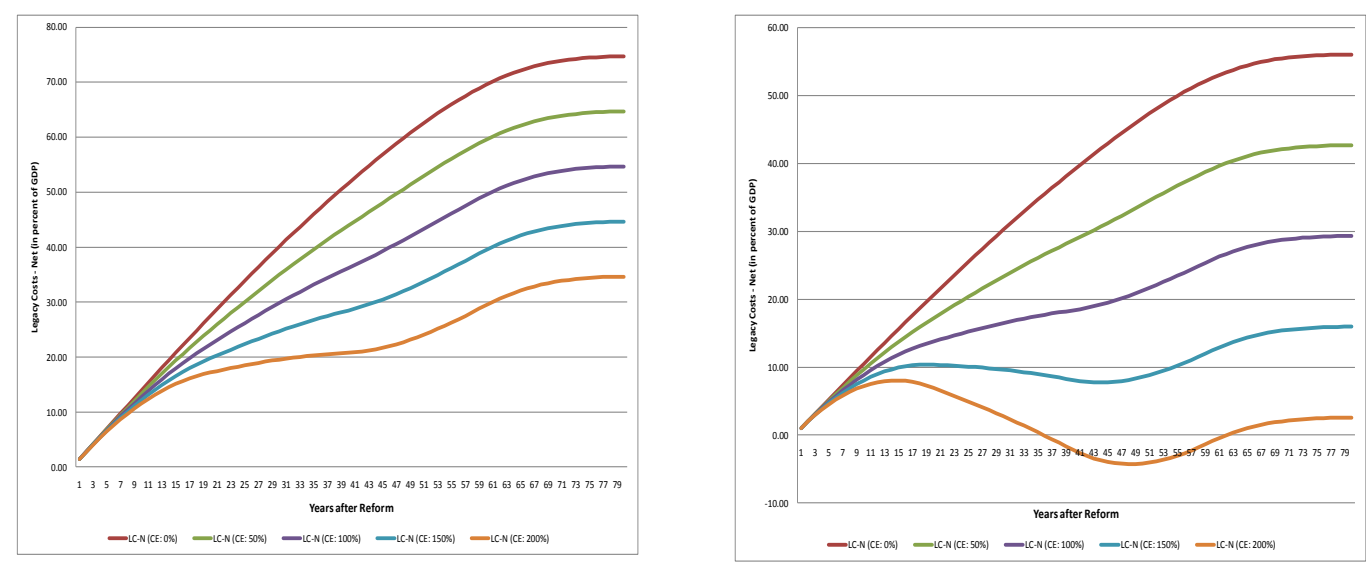

Source: World Bank (2010) 


\section{Concluding remarks}

Summing up, several key elements stand out.

First, to render an NDC reform credible and fully effective in its desired results, it is strictly necessary to determine the legacy costs of the reformed system - no matter how these costs will be financed.

Second, for the reform from an NDB scheme to an NDC scheme wwith a fixed and long-term sustainable contribution rate the definition of legacy costs simply amounts to the actuarial deficit at the time of reform and is finite.

Third, different sources of the legacy deficit may be differentiated, in particular (i) any inherited old legacy costs due to prior reforms of the scheme, (ii) any accrued to date liability due to the inclusion of other schemes with a cost-covering contribution rates above the sustainable new one; and (iii) reforminduced new legacy costs due to the shift toward a lower sustainable contribution rate.

Fourth, distributive effects play both at the intergenerational and intragenerational level, as benefits and costs of the reform are borne unequally by different subgroups of the current and future population.

Fifth, to improve equity and efficiency aspects of an NDC reform it is strongly suggested to address legacy costs in an explicit manner and explore alternative financing mechanisms, such as coverage expansion and well selected general government revenue.

Sixth, in the developing world, one promising way to finance the legacy costs is the use of an increased coverage to strengthen the contribution asset. Avoiding the financing of the legacy costs with earmarked contributions may importantly contribution to such coverage expansion.

Last but not least, for developed countries, theoretical models show that tax financing in particular via indirect taxes such as VAT is an interesting and promising tool, but empirical limitations tend to dampen the real-world usefulness.

\section{References}

Attanasio, O. and G. Weber. 1995. Is Consumption Growth Consistent with Intertemporal Optimization? Evidence from the Consumer Expenditure Survey, Journal of Political Economy, University of Chicago Press, vol. 103(6), 1121-57.

Atkinson, A. and J. Stiglitz. 1976. The design of tax structure: Direct versus indirect taxation, Journal of Public Economics 6(1-2):55-75.

Barr, Nicholas and Peter Diamond. 2009. Pension Reform in China: Issues, Options and Recommendations. Mimeo. December.

Besson, E. 2007. TVA sociale. Ministry of Economy, Finance and Industry, Secrétariat d'état chargé de la prospective et de l'évaluation des politiques publiques, Paris

Botman, D. and M. Kumar. 2007. Global Aging Pressures: Impact of Fiscal Adjustment, Policy Cooperation, and Structural Reforms , IMF Working Paper 07/196

Botman, D. and A. Tuladhar. 2008. Tax and Pension Reform in the Czech Republic-Implications for Growth and Debt Sustainability, IMF Working paper 08/125

Chéron, A., J-O. Hérault and F. Langot. 2008. A quantitative evaluation of payroll tax subsidies for lowwage workers: An equilibrium search approach, Journal of Public Economics, Elsevier, vol. 92(3-4), 817843. 
Diamond, P. 2009. Taxes and Pensions. Boston College, Centre for Retirement Research WP 2009-12

European Union. 2007. Study on reduced VAT applied to goods and services in the Member States of the European Union, Final report prepared by Copenhagen Economics for DG Tax, Brussels

Feldstein, M., E. Ranguelova and A. Samwick. 2001. "The Transition to Investment-based Social Security when Portfolio Returns and Capital Profitability Are Uncertain," in John Y. Campbell and Martin S. Feldstein (eds.) Risk Aspects of Investment Based Social Security Reform. Chicago: University of Chicago Press

Holzmann, Robert. 1998. Financing the Transition to Multipillar, Social Protection Discussion Paper Series, SPDP No. 9808, World Bank, December.

Holzmann, Robert. 1999. On the Economic Benefits and Fiscal Requirements of Moving from Unfunded to Funded Pensions, in: Buti, M., Franco, D. and Pench, L. (1999, eds.): The Welfare State in Europe, Cheltenham, UL. And Northampton, MA (Edward Elgar), 139-196 (Reprint of 1997 Paper).

Holzmann, Robert, Robert Palacios and Asta Zviniene. 2004. Implicit Pension Debt: Issues, Measurement and Scope in International Perspective. Social Protection Discussion Paper Series, SPDP No. 0403, World Bank, March.

Keen, M. and M. Mansour. 2009. Revenue Mobilization in Sub-Saharan Africa: Key Challenges from Globalization, International Monetary Fund, Working Paper 09/157.

Kramarz, F. and T. Philippon. 2001. "The Impact of Differential Payroll Tax Subsidies on Minimum Wage Employment.", Journal of Public Economics, Vol 82 (1): 115-146.

Oksanen, Heikki. 2010. The Chinese pension system - first results on assessing the reform options. Directorate-General for Economic and Financial Affairs, European Commission. Mimeo.

Palmer, Edward. 2006b. Conversion to NDCs - Issues and Models, in Robert Holzmann and Edward Palmer, eds. Pension Reform: Issues and Prospects for Non-Financial Defined Contribution (NDC) Schemes. Washington, DC: World Bank: 169-202.

Palmer, Edward, Daniele Franco, and Agnieszka Chlon-Dominique. 2010. The First Wave of NDC Countries - Taking Stock Ten Plus Years Down the Road - Sweden, Poland, Latvia and Italy; revised conference paper, September.

Robalino, David and Andras Bodor. 2009. On the financial sustainability of earnings-related pension schemes with "pay-as-you-go" financing and the role o government-indexed bonds. Journal of Pension Economics and Finance 8 (2), April: 153-187.

Settergren, Ole and Mikula D. Boguslaw. 2006. The Rate of Return of Pay-As-You-Go Systems: A More Exact Consumption-Loan Model of Interest. In Robert Holzmann and Ed Plamer, eds. opt.cit. Chapter 7, 117-142.

Sin, Yvonne. 2005. China: Pension Liabilities and Reform Options for Old Age Insurance. World Bank Research Working Paper 2005-1.

World Bank.2010. China - A Vision for Pension Policy Reform, Report under finalization, April.

Zheng, Binwen. 2010. "Hybrid" Combination of Social Pooling with Individual Account: A Policy Design of China's Public Pension Based on NDC of Chinese Version. Paper presented the Stockholm NDC conference, December 2-4, 2009; revised conference paper, September. 